\title{
A Smart Colorimetric Platform for Detection of Methanol, Ethanol and Formic Acid
}

\author{
Mizaj Shabil Sha ${ }^{1}{ }^{(0)}$, Muni Raj Maurya ${ }^{1}$, Mithra Geetha ${ }^{1}$, Bijandra Kumar ${ }^{2}$, Aboubakr M. Abdullah ${ }^{1}$ \\ and Kishor Kumar Sadasivuni ${ }^{1, * \mathbb{B}}$
}

1 Center for Advanced Materials, Qatar University, Doha P.O. Box 2713, Qatar; misajmisfa@gmail.com (M.S.S.); muni88_raj@yahoo.co.in (M.R.M.); geethmithramg@gmail.com (M.G.); bakr@qu.edu.qa (A.M.A.)

2 Department of Technology, Elizabeth City State University, Elizabeth City, NC 27909, USA; bkumar@ecsu.edu

* Correspondence: kishor_kumars@yahoo.com

check for updates

Citation: Sha, M.S.; Maurya, M.R.; Geetha, M.; Kumar, B.; Abdullah, A.M.; Sadasivuni, K.K. A Smart Colorimetric Platform for Detection of Methanol, Ethanol and Formic Acid. Sensors 2022, 22, 618. https:// doi.org/10.3390/s22020618

Received: 20 December 2021

Accepted: 8 January 2022

Published: 13 January 2022

Publisher's Note: MDPI stays neutral with regard to jurisdictional claims in published maps and institutional affiliations.

Copyright: (C) 2022 by the authors. Licensee MDPI, Basel, Switzerland. This article is an open access article distributed under the terms and conditions of the Creative Commons Attribution (CC BY) license (https:// creativecommons.org/licenses/by/ $4.0 /)$.

\begin{abstract}
Carbon dioxide $\left(\mathrm{CO}_{2}\right)$ is a greenhouse gas in the atmosphere and scientists are working on converting it to useful products, thereby reducing its quantity in the atmosphere. For converting $\mathrm{CO}_{2}$, different approaches are used, and among them, electrochemistry is found to be the most common and more efficient technique. Current methods for detecting the products of electrochemical $\mathrm{CO}_{2}$ conversion are time-consuming and complex. To combat this, a simple, cost-effective colorimetric method has been developed to detect methanol, ethanol, and formic acid, which are formed electrochemically from $\mathrm{CO}_{2}$. In the present work, the highly efficient sensitive dyes were successfully established to detect these three compounds under optimized conditions. These dyes demonstrated excellent selectivity and showed no cross-reaction with other products generated in the $\mathrm{CO}_{2}$ conversion system. In the analysis using these three compounds, this strategy shows good specificity and limit of detection (LOD, $~ 0.03-0.06 \mathrm{ppm}$ ). A cost-effective and sensitive Internet of Things (IoT) colorimetric sensor prototype was developed to implement these dyes systems for practical and real-time application. Employing the dyes as sensing elements, the prototype exhibits unique red, green, and blue (RGB) values upon exposure to test solutions with a short response time of $2 \mathrm{~s}$. Detection of these compounds via this new approach has been proven effective by comparing them with nuclear magnetic resonance (NMR). This novel approach can replace heavy-duty instruments such as high-pressure liquid chromatography (HPLC), gas chromatography (G.C.), and NMR due to its extraordinary selectivity and rapidity.
\end{abstract}

Keywords: carbon dioxide; electrochemical conversion; methanol; ethanol; formic acid

\section{Introduction}

Carbon dioxide is a gas that occupies $0.03 \%$ of the air volume. The release of large amounts of $\mathrm{CO}_{2}$ into the atmosphere every day in many ways contributes to the greenhouse effect, which warms the atmosphere to provide the conditions needed to sustain life. It is estimated that by 2100 , anthropogenic $\mathrm{CO}_{2}$ levels may reach $590 \mathrm{ppm}$, increasing global temperatures by $1.9^{\circ} \mathrm{C}$ [1]. The Intergovernmental Panel on Climate Change (IPCC) has recommended $350 \mathrm{ppm} \mathrm{CO}$ as the maximum safe level for atmospheric greenhouse gas concentrations. The Paris Agreement aims to decrease atmospheric $\mathrm{CO}_{2}$ levels by 2050 in most countries [2,3]. $\mathrm{CO}_{2}$ conversion, therefore, becomes a viable option to address this without interfering with the development of the urbanization process [4]. The products of $\mathrm{CO}_{2}$ conversion can also be used for industrial chemicals production or energy production. As a result, this can complete the carbon cycle (C-cycle) and generate energy while reducing greenhouse gases in the environment [5]. María J et al. designed a novel process that produces green gasoline on an industrial scale [6]. Qingchun Yang et al. proposed four co-feed processes of coal and coke oven gas to ethylene glycol with different methane reforming technologies: steam reforming, dry reforming, combining steam and dry reforming, and 
tri-forming of methane technologies [7]. i-Suhailah Rosli et al. proposed modeling the attached growth of Chlorella vulgaris onto polyurethane foam support material in a fluidized bed bioreactor while simultaneously bioremediating real nutrient-rich wastewater and bio fixing $\mathrm{CO}_{2}$ for biodiesel production [8].

Sustainable societies require that chemical commodities be obtained in an environmentally friendly and energy-efficient way. $\mathrm{CO}_{2}$ conversion into value-added chemicals has a clear long-term goal [9]. However, this can only be achieved using highly active and selective catalytic processes under favorable circumstances [10]. $\mathrm{CO}_{2}$ conversion products can supplement chemical feedstocks used in industry and cut the cost of transportation. $\mathrm{CO}_{2}$ has its advantages, including affordability and nontoxicity, renewable energy sources, increased productivity, and cost-effectiveness [11]. Despite its scientific challenges, carbon dioxide conversion has significant benefits. Chemically and thermodynamically, $\mathrm{CO}_{2}$ is a very stable molecule. Consequently, $\mathrm{CO}_{2}$ conversion reactions are endothermic and require efficient catalysts to achieve high yields [12]. Various strategies have been used to convert $\mathrm{CO}_{2}$, including thermal catalysis, photocatalysis, electrocatalysis, photoelectrochemical reactions, thermocatalysis, radiolysis, and geological storage [13].

Electrochemical reduction of carbon dioxide is typically achieved by coating an electrode with catalytic ink. Electrons are transferred by applying a sufficient voltage. Faradaic efficiency, overpotential, and current density are the most relevant metrics for $\mathrm{CO}_{2}$ conversion. Carbon dioxide chemical bonds can be broken by electron and proton pairs [14]. Various compounds, including hydrocarbons, can be produced via $\mathrm{CO}_{2}$ conversion, depending on the catalyst used. Copper electrodes can electrochemically reduce $\mathrm{CO}_{2}$ to form $C_{1}$ products (formic acid and methanol) and $C_{2}$ products (ethanol) [15]. The compounds can be detected using classic chemical, enzymatic, chemo sensing, and biosensing methods [16-19]. Formic acid (formate) is the main reason for toxicity and death through methanol poisoning. The simultaneous determination of methanol, ethanol, and formate in the body can help discover the cause of death and is useful in diagnosing acute methanol poisoning [20].

Current methods are not selective or sensitive enough, and some are extremely costly. These methods require external detection of the species that result from $\mathrm{CO}_{2}$ reduction. In terms of dynamics, ex situ detection has been found challenging to analyze. Therefore, it is imperative to develop sensitive and specific methods for detecting these compounds [21]. Colorimetry involves replacing subjective responses to colors with an objective numerical system $[22,23]$. Colorimetry quantitates the nature of the illumination and the object's optical properties, leading to RGB color representations [24]. Compared to other methods, this method has obvious advantages, including affordability, simplicity, and fast response [25].

This study proposes a colorimetric detection integrated with a simple smartphoneassisted technique based on dyes systems to provide dynamic identification of $\mathrm{CO}_{2}$ conversion products, such as formic acid, methanol, and ethanol, and unique mechanistic insight. The simplest oxygenates produced by $\mathrm{CO}_{2}$ conversion are formic acid and methanol. Formic acid, methanol, and ethanol selectivity largely depend on the reduction methods and catalysts. The research aims to determine the presence of these compounds quickly and easily by colorimetry integrated with the IoT platform.

\section{Experiments and Methods}

\subsection{Materials and Instruments}

Formic acid (99.5\%), methanol (99.5\%), and ethanol (99.5\%) were purchased from BDH Ltd. Pool England. Acquiring potassium permanganate ( $99 \%)$, eosin blue $(90 \%)$, phenyl red, methyl orange, methyl red, and alizaringelb G.G. was done via E. Merck, Darmstadt, Germany. Acetone (99\%), DME (25\%), formaldehyde (99\%), salicylic acid, urea, iodine, dimethyl sulfoxide (DMSO), deuterated water $\left(\mathrm{D}_{2} \mathrm{O}\right)$, and sodium hydroxide were obtained from Research-Lab Fine Chem Industries, Mumbai, India for selectivity analysis and iodoform test. The experiments were conducted with deionized (DI) water from the Millipore Milli-Q water system. All reagents used in the study were of analytical 
grade. A Biochrom UV spectrophotometer (Biochrom Ltd., Cambridge, United Kingdom) with a 300-750 nm scanning range was used for the characterization. The electrochemical experiment was conducted with a Gamry electrochemical analyzer (reference 3000, Gamry instruments, Warminster, PA, USA). Molecular identity analysis was performed using the Spinsolve benchtop NMR spectrometer by magritek, Malvern, PA, USA.

For fabricating sensors, Arudino UNO, Adafruit LCD shield (both made in the Adafruit Industries, New York, NY, USA), LEDs (peak around $606 \mathrm{~nm}$ ), resistors, TSL230R light-to-frequency sensor, protoboard, conductors (Cat 5 cable), and Black ABS or PLA filament were used. The case was printed by a QIDI 3D printer (Zhejiang QIDI Technology Co., Ltd., Ruian, China) to protect sensing elements.

\subsection{Methods}

\subsubsection{Dye Preparation and Analysis}

The solutions of $\mathrm{KMnO}_{4}$, eosin blue, phenyl red, methyl orange, methyl red, and alizaringelb G.G. were prepared at a concentration of $0.003 \mathrm{M}$ and used throughout the experiment. The $\mathrm{pH}$ effect of the different test analytes with different dye solutions was analyzed in acidic $(2,4,6)$, neutral, and basic $(9,12)$ solutions. Each dye solution $(10 \mathrm{~mL})$ was treated with $1 \mathrm{~mL}$ of $0.5 \mathrm{ppm}$ test solution (ethanol/formic acid/methanol) separately in the adjusted $\mathrm{pH}$. Changes in color and corresponding response time were observed. These test solutions' concentration and temperature effects in selected dyes were investigated with visible color change at a certain $\mathrm{pH}$ (which varied for different dyes). The detection limit of the dyes was monitored with $0.05-15$ ppm concentrations of test solutions, and temperature effect was studied at $25^{\circ} \mathrm{C}, 50{ }^{\circ} \mathrm{C}, 75^{\circ} \mathrm{C}$, and $100{ }^{\circ} \mathrm{C}$. The iodoform test was performed to identify the detected compound, as some dyes can detect both methanol and ethanol. During the analysis, $0.5 \mathrm{M}$ iodine solution $(25 \mathrm{~mL})$ and $1 \mathrm{M}$ sodium hydroxide $(10 \mathrm{~mL})$ were added to $10 \mathrm{~mL}$ of dye solution containing $0.5 \mathrm{ppm}$ methanol or ethanol. Selectivity analysis was performed using 0.5 ppm of major compounds from each class of organic molecules (acetone for ketones, dimethyl ether (DME) for ethers, formaldehyde for aldehydes, salicylic acid for acids, and urea for amides) at room temperature.

\subsubsection{Fabrication of Sensor Prototype}

A sensitive IoT-based colorimetric sensor prototype was developed to apply this novel technique, and the schematic representation of the prototype is shown in Figure 1. Three cuvettes were placed in series for the setup, and three different dye solutions were employed as sensing elements in these cuvettes. A vital light source with four lights (red, blue, white, and green) was placed at one end, and a color detector was placed at the opposite end. An Arduino nano-controlled illumination of the light source was used via an external switch. The subsequent triggering of the external switch sequentially illuminates the test chamber with white, blue, red, and green light. A portable battery powers the detector, and the RGB data is acquired using a mobile application. The detector identified color changes in dye solutions placed inside the cuvettes upon exposure to test solutions. It showed unique RGB values in the device connected to the sensor prototype through Bluetooth.
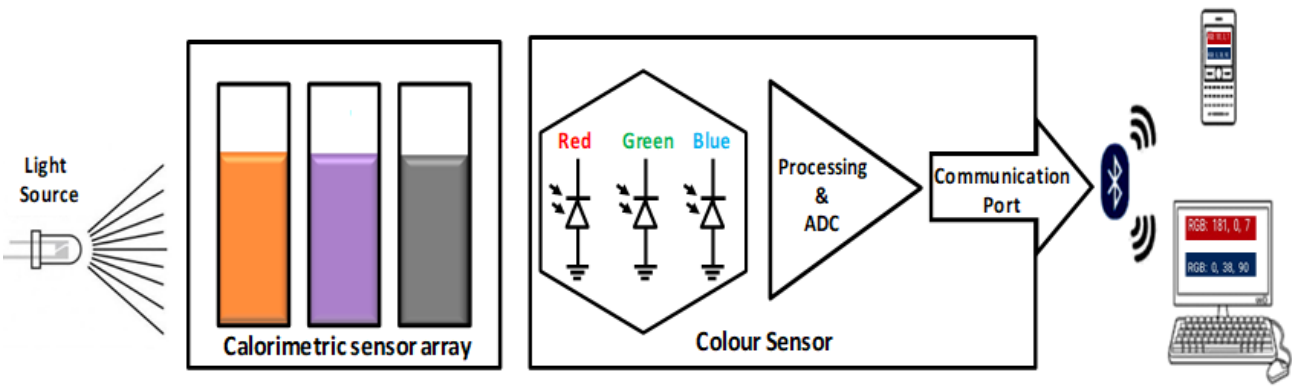

Figure 1. Fabricated sensor prototype for colorimetry. 


\subsubsection{Characterization, Electrochemical Analysis, and Quantification}

A UV-Vis spectrophotometer performed all the characterization. Electrochemical measurements of the $\mathrm{CO}_{2}$ conversion were conducted using $0.5 \mathrm{M}$ of $\mathrm{Na}_{2} \mathrm{HCO}_{3}$ for 15 min at room temperature. The counter, reference, and working electrode were platinum wire, $\mathrm{Ag} / \mathrm{AgCl}$ (3 $\mathrm{M} \mathrm{KCl}$ solution), and copper electrode, respectively, with a diameter of $5 \mathrm{~mm}$. Amperometric measurements were conducted with a potential range of $0.5-0.8 \mathrm{~V}$ vs. a reference electrode and a sweep rate of $5 \mathrm{mV} / \mathrm{s}$. The liquid products were quantified by $\mathrm{NMR}$ spectroscopy using $0.5 \mathrm{~mL}$ electrolyte $(0.1 \mathrm{~N} \mathrm{NaOH})$ with $0.1 \mathrm{~mL} \mathrm{D}_{2} \mathrm{O}$ (deuterated water) and $0.5 \mu \mathrm{L}$ dimethyl sulfoxide (DMSO) as an internal standard.

\section{Results and Discussion}

\subsection{Detection of Formic Acid}

\subsubsection{Response Time and $\mathrm{pH}$ Effect}

$\mathrm{pH}$ effect of the test solution $(0.5 \mathrm{ppm})$ at room temperature on a series of dye solutions with various $\mathrm{pH}$ values $(2,4,6,7,9$, and 12$)$ was examined. Data were analyzed before and after adding the test solutions to the dyes at various $\mathrm{pH}$ values in each dye.

In the alizaringelb dye solution, a significant visible color change was noticed in $\mathrm{pH} 6$ and 7 after adding 0.5 ppm formic acid (Figure $2 \mathrm{~b}$ ). The color changed from yellow to light yellow in $\mathrm{pH} 6$ and yellow to orange in $\mathrm{pH} 7$. It was confirmed by the emergence of a new absorption band centered at $\sim 474 \mathrm{~nm}$ from $\sim 476 \mathrm{~nm}$ in the case of $\mathrm{pH} 6$ and $\sim 514 \mathrm{~nm}$ from $495 \mathrm{~nm}$ for $\mathrm{pH} 7$ in UV-Vis absorbance spectra (Figure 2a). A color change was observed in pH 9 and 12 eosin blue dye solution after adding 0.5 ppm formic acid (Figure 2d). Color change from red to orange in $\mathrm{pH} 9$ and from red to pink in $\mathrm{pH} 12$ was observed, and as a result, a slight decrease in absorbance variation at $\sim 513 \mathrm{~nm}$ was observed for $\mathrm{pH} 9$. For $\mathrm{pH} 12$, the new absorption band with the absorbance of $0.2 \mathrm{a} . \mathrm{u}$. centered at $\sim 532 \mathrm{~nm}$ from $\sim 516 \mathrm{~nm}$ was detected in the UV-Vis absorption spectrum (Figure 2c).

In the case of $\mathrm{KMnO}_{4}$, the bare dye solution exhibited a violet color in all $\mathrm{pH}$, and after the addition of $0.5 \mathrm{ppm}$ formic acid at $\mathrm{pH} 2$, showed a color shift to red (Figure 2f), which was also confirmed by the new absorption band centered at $\sim 564 \mathrm{~nm}$ from $\sim 545 \mathrm{~nm}$ with the absorbance of 1.02 a.u. (Figure 2e). Two absorption peaks appeared in $\mathrm{KMnO}_{4}$. This phenomenon is common for highly conjugated systems. However, it is often solventdependent and might be due to electronic transitions between the different vibrational energy levels possible for each electronic state [26]. Phenyl red dye solution changed dramatically in color when formic acid was added at $0.5 \mathrm{ppm}$ to $\mathrm{pH} 2,4,6$, and 7 (Figure $2 \mathrm{~h}$ ). The color change was confirmed by the appearance of new absorption bands centered at $\sim 581 \mathrm{~nm}$ from $\sim 560 \mathrm{~nm}$ in all the effective $\mathrm{pH}$ without any variation in absorbance as it was with bare dye solution, at $\mathrm{pH} 2,4,7$ and $\mathrm{pH} 6$ with the test solution (Figure 2g).

These UV-Vis analyses showed a bathochromic effect after adding test solutions in each dye at a certain $\mathrm{pH}$ [27]. The change in absorbance to a longer wavelength might be caused due to presence of the auxochrome (test solution), which may change in solvent polarity. The observable color change offers a convenient approach to detecting formic acid via unaided eyes. Alizaringelb, eosin blue, phenyl red, and potassium permanganate efficiently detected formic acid with a short detection time. Compared to the other two dyes, phenyl red and alizaringelb detect formic acid extremely rapidly (Table 1). Methanol and ethanol analyses in these dyes demonstrated excellent specificity and selectivity for formic acid alone. 
a)

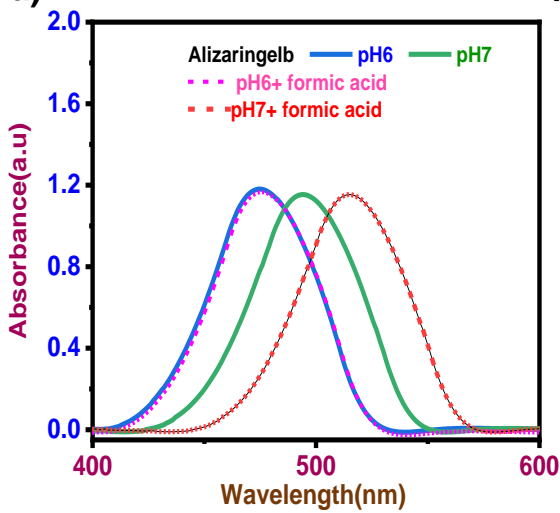

c)

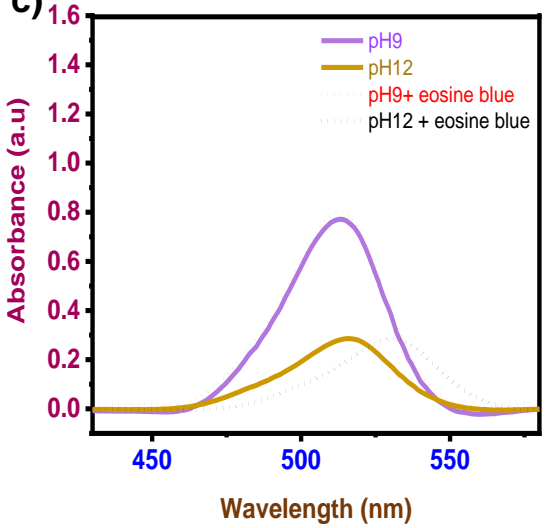

e)

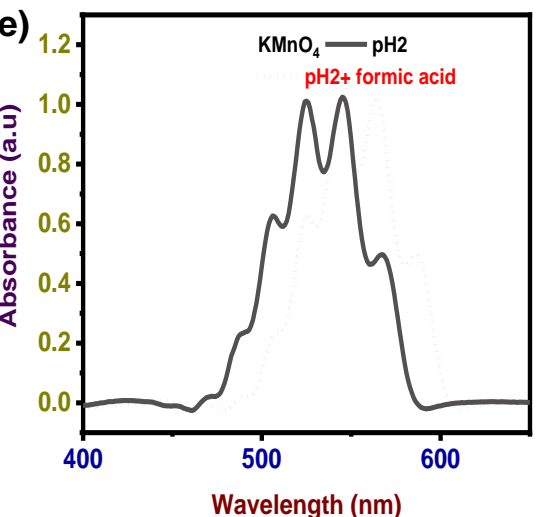

b)

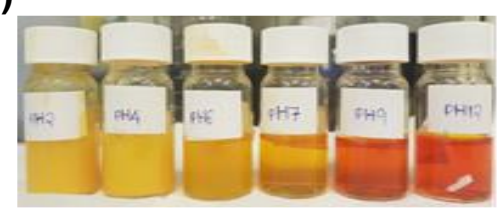

Alizaringelb before adding 0.5 ppm Formic acid

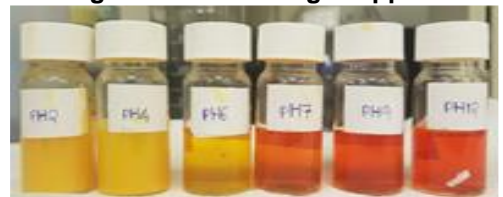

Alizaringelb after adding $\mathbf{0 . 5}$ ppm Formic acid

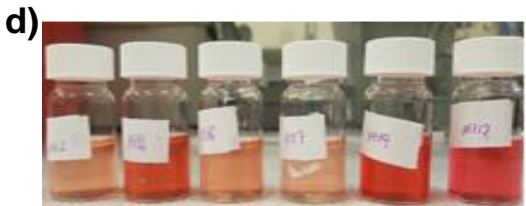

Eosin blue before adding $\mathbf{0 . 5}$ ppm Formic acid

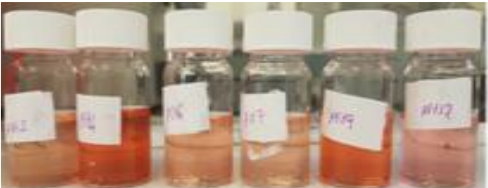

Eosin blue after adding 0.5 ppm Formic acid

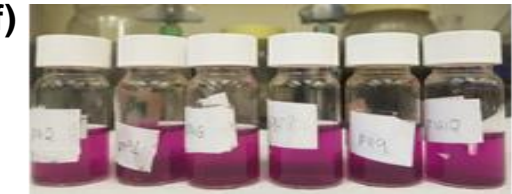

$\mathrm{KMnO}_{4}$ before adding 0.5 ppm Formic acid

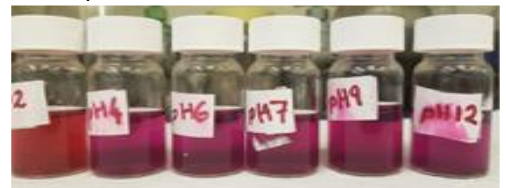

$\mathrm{KMnO}_{4}$ after adding $0.5 \mathrm{ppm}$ Formic acid

h)

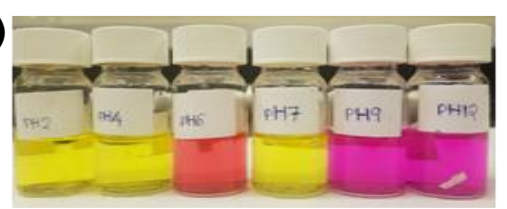

Phenyl red before adding $\mathbf{0 . 5}$ ppm Formic acid

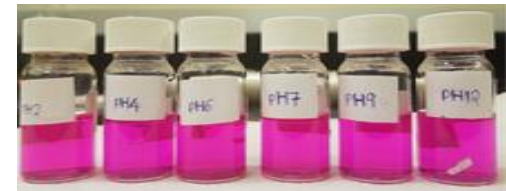

Phenyl red after adding $\mathbf{0 . 5}$ ppm Formic acid

Figure 2. $\mathrm{pH}$ effect of formic acid (a,c,e,g) UVVis absorption curve of dyes in effective $\mathrm{pH}$ after adding $0.5 \mathrm{ppm}$ formic acid. $(\mathbf{b}, \mathbf{d}, \mathbf{f}, \mathbf{h}) \mathrm{pH}$ adjusted dye solution at room temperature before and after adding 0.5 ppm formic acid. 
Table 1. Colorimetric detection of formic acid.

\begin{tabular}{|c|c|c|c|c|}
\hline Sl. No & Dye Solution & Dye Structure & Detected $\mathrm{pH}$ and Color Change & Response Time \\
\hline 1 & Eosin blue & & $\begin{array}{c}\text { pH } 9 \text { (red to orange), } \\
\text { pH } 12 \text { (red to pink) }\end{array}$ & $10 \mathrm{~min}$ \\
\hline 2 & Phenyl red & & $\begin{array}{c}\mathrm{pH} \text { 2, 4, } 7 \text { (yellow to magenta) } \\
\text { pH } 6 \text { (red to magenta) }\end{array}$ & $2 \mathrm{~s}$ \\
\hline 3 & $\begin{array}{l}\text { Potassium } \\
\text { permanganate }\end{array}$ & & pH 2 (violet to red) & $2 \mathrm{~min}$ \\
\hline 4 & Alizaringelb GG & & $\begin{array}{c}\text { pH } 6 \text { (yellow to light yellow) } \\
\text { pH } 7 \text { (yellow to orange) }\end{array}$ & $3 \mathrm{~s}$ \\
\hline
\end{tabular}

Eosin blue is a dibromo dinitro derivate of fluorescein. Such molecules composed of two similar atoms or groups of atoms unite with a conjugated system of double carbon linking at the one and four positions. The reactions are $\mathrm{pH}$-specific, but the union does not follow Thiele's law. This might account for the color change, which occurred only at $\mathrm{pH} 9$ and 12 after adding formic acid and eosin blue, from red to orange and pink, respectively.

Phenol red changes from yellow to red over $\mathrm{pH} 6$ and then turns to magenta above neutral $\mathrm{pH}$. The phenol red dye may react to form complexes, causing a $\mathrm{pH}$ change in the reaction system with formic acid, resulting in a color change. Phenol red loses its proton if the $\mathrm{pH}$ level in the reaction system is above $6(\mathrm{pKa}=1.2)$, resulting in the red, negatively charged ion. The color change from red to magenta occurs at a $\mathrm{pH}$ that is still higher than neutral $(\mathrm{pKa}=7.7)$. In the presence of formic acid, the absorbance intensity of potassium permanganate decreased, indicating that formic acid complexes form due to oxidation in which the acid molecule might act as a reactant with potassium permanganate.

\subsubsection{Concentration Effect}

To analyze the sensitivity of the dyes towards the test solution, the UV spectrometric study was carried out by varying the test analyte concentration from $0.05-15 \mathrm{ppm}$ in particular reactive $\mathrm{pH}$ of the dyes at ambient temperature. The corresponding calibration plot for estimating the dye limit of detection (LOD) towards each test analyte sensing is shown in Figure 3a. The calibration curve was plotted by considering the peak absorbance of each dye for different concentrations of specific test analytes. The absorbance peak for different dyes was $495 \mathrm{~nm}$ for alizaringelb, $513 \mathrm{~nm}$ for eosin blue, $564 \mathrm{~nm}$ for $\mathrm{KmnO}_{4}$, and $581 \mathrm{~nm}$ for phenyl red. Linear fitting was performed in the range of $0.05 \mathrm{ppm}$ to $15 \mathrm{ppm}$ to estimate the LOD using the equation

$$
\mathrm{LOD}=\frac{3 \sigma}{\mathrm{m}}
$$


where $\mathrm{m}$ represents the slope of the calibration plot and $\sigma$ is the standard deviation of the intercept. The linear fitting estimated an LOD of alizaringelb as $\sim 0.059 \mathrm{ppm}, \mathrm{R}^{2}=0.997$. Similarly, the LOD of eosin blue for formic acid was $\sim 0.053 \mathrm{ppm}$ with $\mathrm{R}^{2}=0.927$. In the case of $\mathrm{KmnO}_{4}$ for different concentrations of formic acid in the range of 0.05-15 ppm, the estimated LOD was $\sim 0.051 \mathrm{ppm}, \mathrm{R}^{2}=0.947$. The estimated LOD of phenyl red was $\sim 0.060 \mathrm{ppm}, \mathrm{R}^{2}=0.977$. The sensitivity investigation indicates that all these dyes exhibit a high sensitivity towards formic acid with a linear detection limit as low as $\sim 0.05 \mathrm{ppm}$ in the selected concentration range (Figure 3a). This concentration study indicated that these dyes exhibit high sensitivity towards formic acid even at low concentrations. Figure 3a shows that absorbance increases, following the Lambert-Beer law, as concentration increases. Table 2 represents the response time taken by different dye solutions at reactive $\mathrm{pH}$ for different concentrations of formic acid varying from $0.05-15 \mathrm{ppm}$.
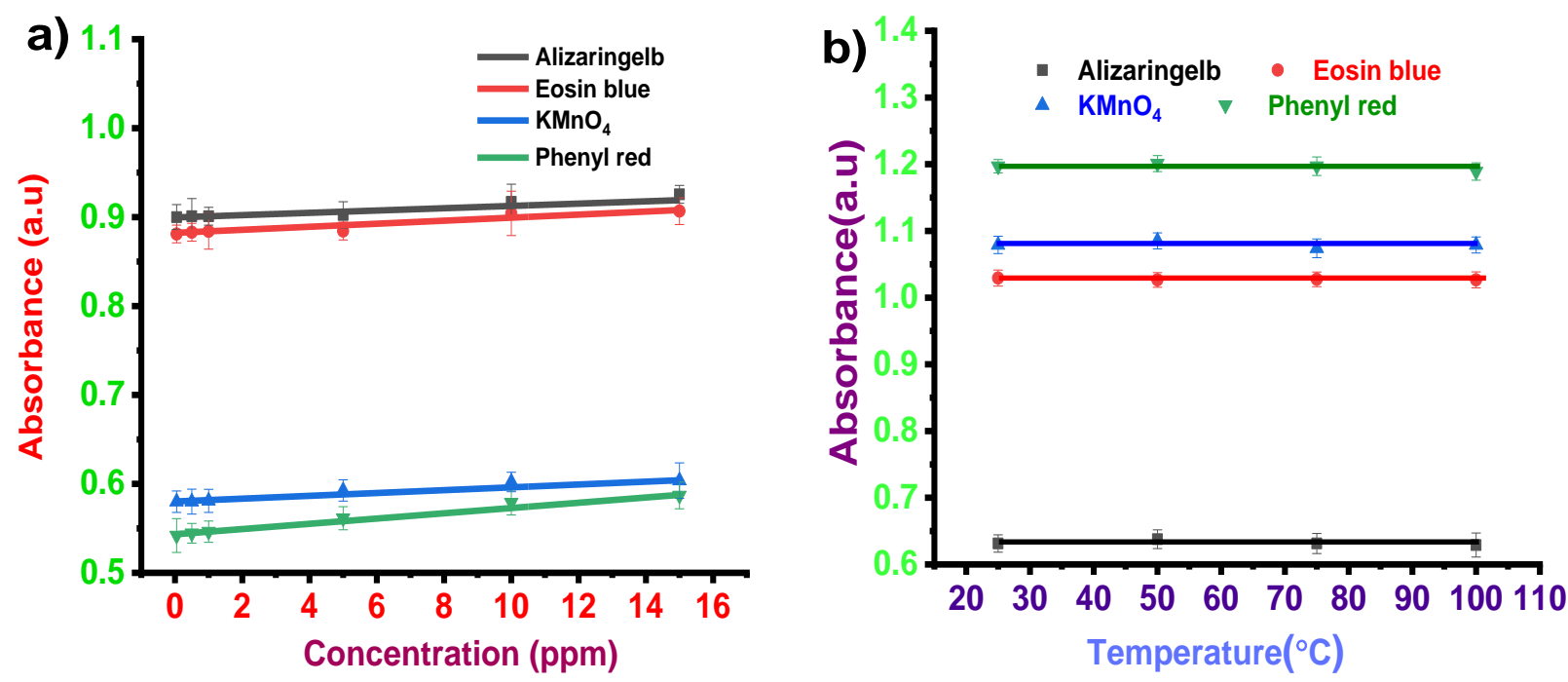

Figure 3. (a) Sensitivity analysis of formic acid in dye solutions. (b) Stability analysis of formic acid in dye solutions.

Table 2. Response time of dyes for different concentrations of formic acid.

\begin{tabular}{|c|c|c|c|c|c|c|c|}
\hline \multirow{2}{*}{ S1. No } & \multirow{2}{*}{ Dye Solution } & \multicolumn{6}{|c|}{ The Concentration of Formic Acid in ppm } \\
\hline & & 0.05 & 0.5 & 1 & 5 & 10 & 15 \\
\hline 1 & Eosin blue ( $\mathrm{pH} 9$ ) & - & $10 \mathrm{~min}$ & $8 \mathrm{~min}$ & $6 \min 40 \mathrm{~s}$ & $2 \mathrm{~min}$ & $\begin{array}{l}\text { Fraction of } \\
\text { seconds }\end{array}$ \\
\hline 2 & Phenyl red (pH 7) & - & $2 \mathrm{~s}$ & $\begin{array}{l}\text { Fraction of } \\
\text { seconds }\end{array}$ & $\begin{array}{l}\text { Fraction of } \\
\text { seconds }\end{array}$ & $\begin{array}{l}\text { Fraction of } \\
\text { seconds }\end{array}$ & $\begin{array}{l}\text { Fraction of } \\
\text { seconds }\end{array}$ \\
\hline 3 & $\begin{array}{c}\text { Potassium } \\
\text { permanganate }(\mathrm{pH} 2)\end{array}$ & - & $2 \mathrm{~min}$ & $1 \min 43 \mathrm{~s}$ & $1 \mathrm{~min}$ & $7 \mathrm{~s}$ & $\begin{array}{l}\text { Fraction of } \\
\text { seconds }\end{array}$ \\
\hline 4 & Alizaringelb GG ( $\mathrm{pH}$ 7) & - & $3 \mathrm{~s}$ & $\begin{array}{l}\text { Fraction of } \\
\text { seconds }\end{array}$ & $\begin{array}{c}\text { Fraction of } \\
\text { seconds }\end{array}$ & $\begin{array}{c}\text { Fraction of } \\
\text { seconds }\end{array}$ & $\begin{array}{c}\text { Fraction of } \\
\text { seconds }\end{array}$ \\
\hline
\end{tabular}

\subsubsection{Temperature Effect}

One of the most important properties for a sensing application is the system's stability towards the change in temperature of the surrounding medium. Thus, to investigate the stability of the dye's response to the change in temperature, the dye solutions were subjected to different temperatures, and sensing towards the corresponding compounds was analyzed. To understand the effect of temperature, test solution $(0.5 \mathrm{ppm})$-dye mixture at effective $\mathrm{pH}$ was heated at different temperatures: $25^{\circ} \mathrm{C}, 50^{\circ} \mathrm{C}, 75^{\circ} \mathrm{C}$, and $100{ }^{\circ} \mathrm{C}$. In general, for a proper sensing mechanism, the temperature effect should be negligible in 
the dye system. Figure $3 b$ shows the effect of temperature on the sensing performance of selected dyes towards 0.5 ppm of test solutions. It is noticeable that the absorbance of all the dyes treated with different temperatures did not exhibit any deviation during stability analysis. Response time was almost the same for dye solutions at different temperatures.

\subsubsection{Selectivity}

One of the most important characteristics of a detection device is its ability to detect the target selectively. The selectivity of the proposed platform was tested with possible interfering molecules. All the six dyes, namely alizaringelb G.G. ( $\mathrm{pH} 7$ ), potassium permanganate ( $\mathrm{pH}$ ), eosin blue ( $\mathrm{pH}$ 9), phenyl red ( $\mathrm{pH} 7)$, methyl orange ( $\mathrm{pH} 9$ ), and methyl red ( $\mathrm{pH} 9$ ), were tested using acetone, DME, formaldehyde, salicylic acid, and urea. UV analysis showed that the four other dyes could detect formic acid except for methyl red and orange. The visible color change was not obtained with the above compounds in methyl red and methyl orange, confirming formic acid's selectivity with these dyes. Methanol and ethanol were detected by methyl orange and methyl red solution. Subsequently, feasibility verification of these dyes' selectivity was confirmed by measuring the relative change in the wavelength $(\Delta \lambda)$ from UV-Vis analysis estimated by the equation below.

$$
\Delta \lambda=\frac{\lambda x-\lambda_{0}}{\lambda_{0}} \times 100
$$

where $\lambda x$ is the wavelength of peak absorbance measured in the presence of the analyte and $\lambda_{0}$ is the wavelength of peak absorbance of the blank solution. The peak absorbance wavelength $(\lambda x)$ for different dyes was $495 \mathrm{~nm}$ for alizaringelb, $513 \mathrm{~nm}$ for eosin blue, $564 \mathrm{~nm}$ for $\mathrm{KMnO}_{4}$, and $581 \mathrm{~nm}$ for phenyl red. It is clear from Figure 4 that all the dyes have additional selectivity and specificity in detecting formic acid generated by the electrochemical conversion of $\mathrm{CO}_{2}$. Moreover, the above results confirmed that these dye systems could develop a colorimetric strategy.
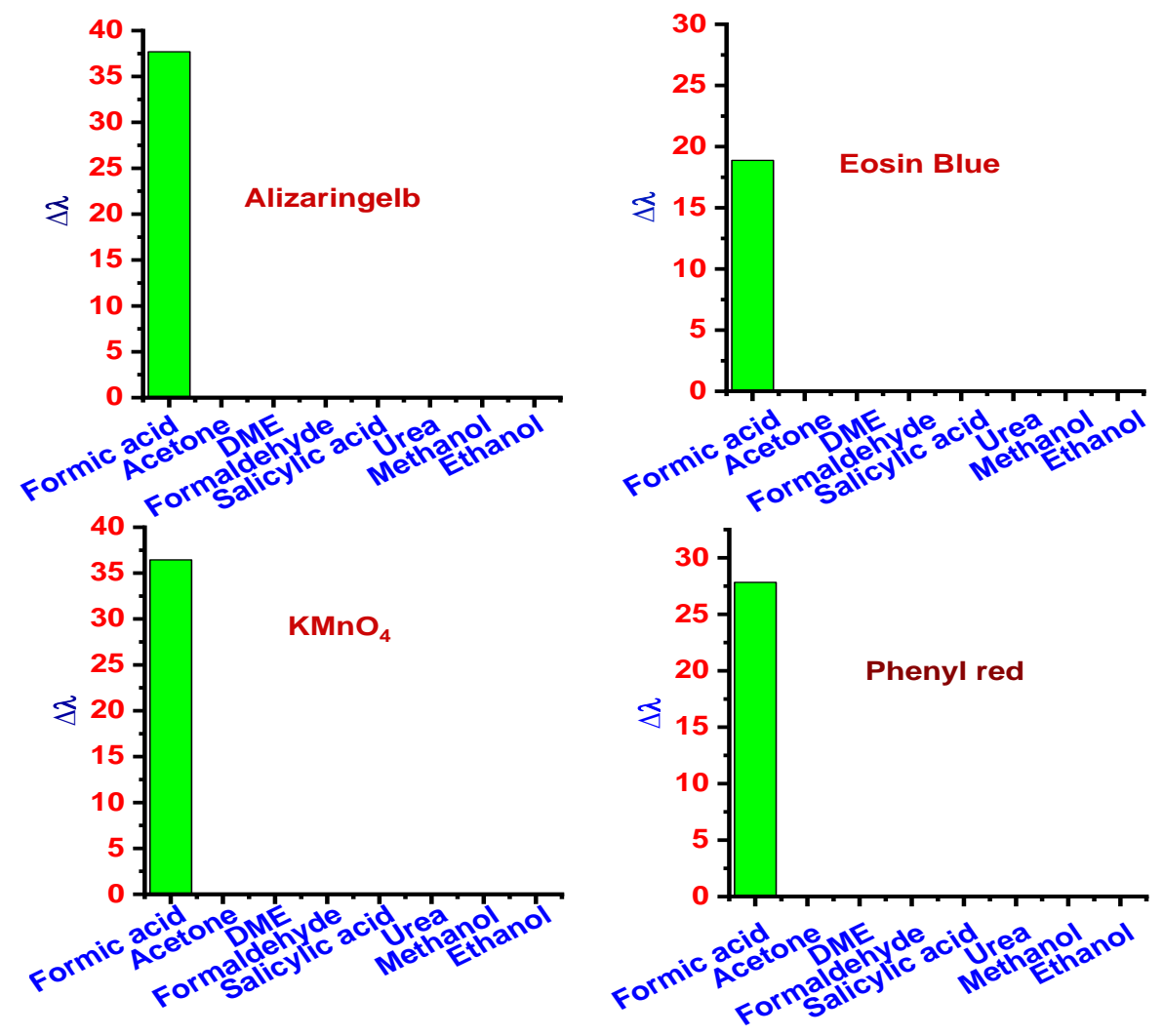

Figure 4. Selectivity analysis of formic acid in alizaringelb, eosin blue, $\mathrm{KMnO}_{4}$, and phenyl red. 


\subsection{Detection of Methanol}

\subsection{1. $\mathrm{pH}$ Effect}

No distinct visible color change was observed in the case of methyl orange and methyl red with a test solution of $0.5 \mathrm{ppm}$ methanol. Even though methanol produced no visible color change in methyl red and methyl orange, the UV-Vis analysis showed a peak shift. In the case of methanol-methyl orange mixture, new absorption bands centered at $\sim 485 \mathrm{~nm}$ from $\sim 459 \mathrm{~nm}$ in $\mathrm{pH} 9$ with the absorbance of 0.132 a.u., as that of bare dye solution, and with $\mathrm{pH} 12$, the new absorption band obtained at $\sim 482 \mathrm{~nm}$ from $460 \mathrm{~nm}$ with the absorbance of 0.155 a.u. (Figure $5 \mathrm{a}$ ). In the case of methanol-methyl red mixture, UV-Vis analysis peak shift was obtained at $\mathrm{pH} 2,4(\sim 489 \mathrm{~nm}$ to $\sim 509 \mathrm{~nm})$, and $6(\sim 493 \mathrm{~nm}$ to $510 \mathrm{~nm})$ with the same absorbance of 0.60 a.u., 0.581 a.u., and 0.355 a.u., respectively (Figure $5 \mathrm{~b}$ ).
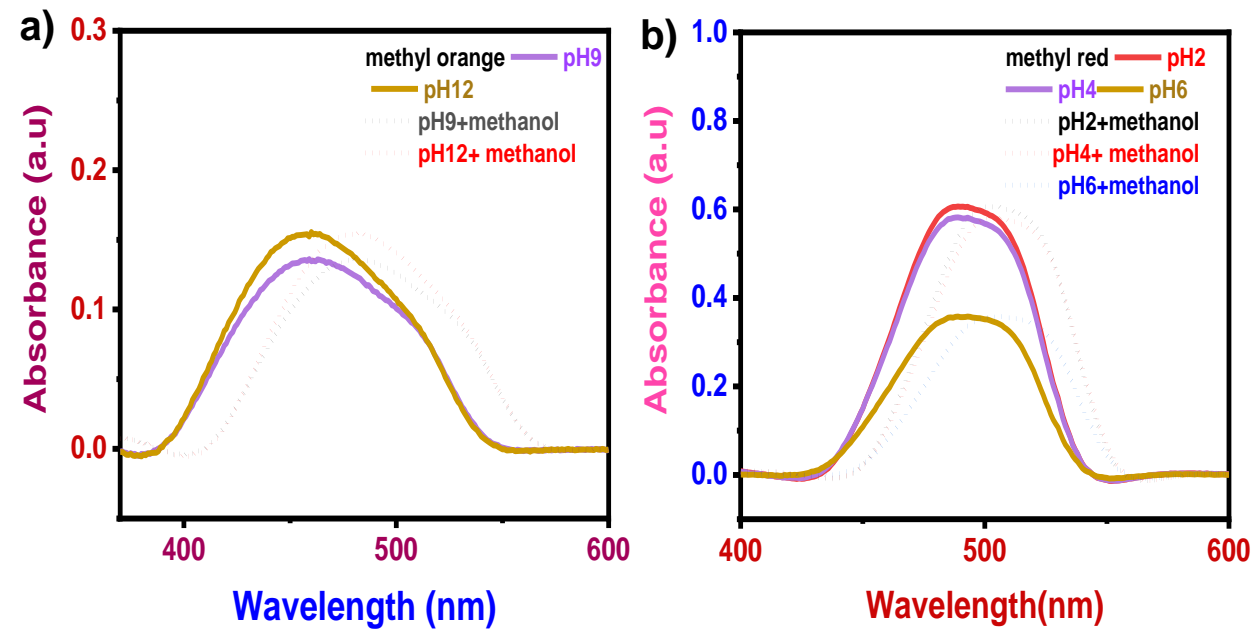

Figure 5. pH effect: (a) Methyl orange dye before and after adding methanol; (b) methyl red dye before and after adding methanol.

\subsubsection{Concentration Effect}

Similar to formic acid, the effect of different concentrations (0.05-15 ppm) of methanol on methyl orange and methyl red dye was examined (Figure 6a). The linear fitting by considering the peak absorbance of methyl orange at $485 \mathrm{~nm}$ for different concentrations of methanol estimated LOD as $\sim 0.0375 \mathrm{ppm}, \mathrm{R}^{2}=0.937$. Similarly, the calibration plot of methyl red at $515 \mathrm{~nm}$ for different methanol concentrations estimated an LOD of $\sim 0.0318 \mathrm{ppm}, \mathrm{R}^{2}=0.955$.
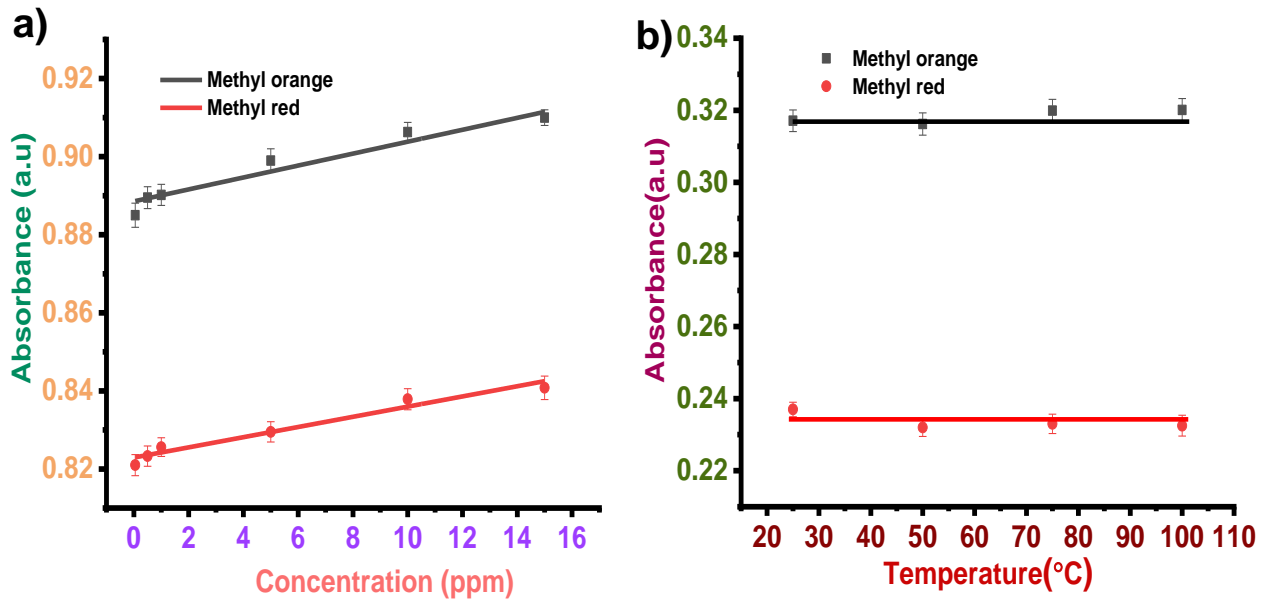

Figure 6. (a) Sensitivity analysis of methanol in dye solutions. (b) Stability analysis of methanol in dye solutions. 


\subsubsection{Temperature Effect}

Stability analysis of methanol in methyl orange and methyl red showed a negligible temperature effect. Figure $6 b$ shows the effect of temperature on the sensing performance of methyl orange and methyl red dye solutions towards $0.5 \mathrm{ppm}$ methanol.

\subsubsection{Selectivity Analysis}

Feasibility verification of these dyes' selectivity was confirmed by measuring the relative change in the wavelength $(\Delta \lambda)$ from UV-Vis analysis estimated by Equation (2). Analysis was carried out in pH 9 methyl orange dye solution and pH 6 methyl red dye solution (Figure 7). It is clear from Figure 7 that these two dyes have additional selectivity and specificity in detecting methanol.

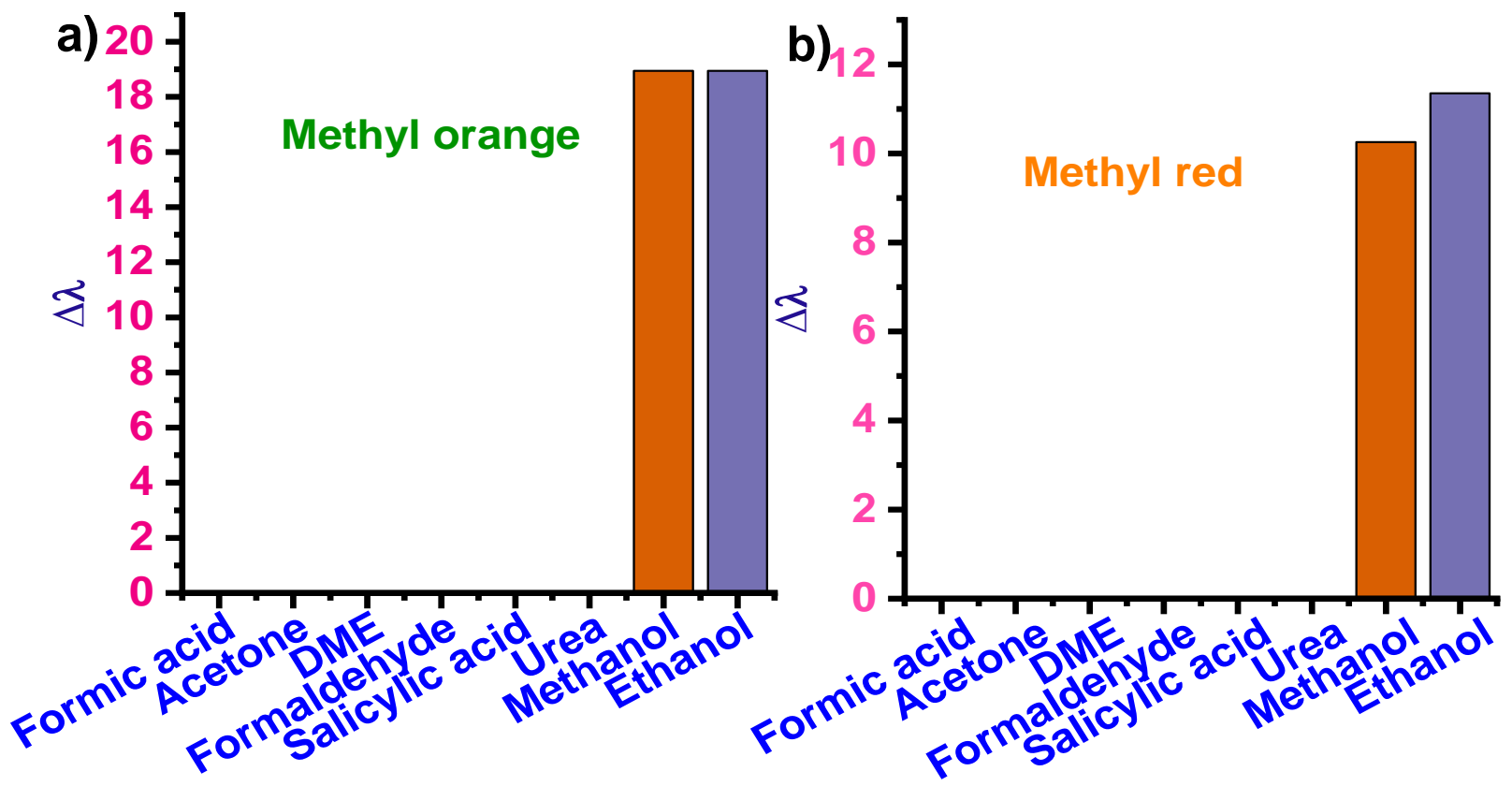

Figure 7. Selectivity analysis in (a) methyl orange and (b) methyl red dye solutions.

\subsection{Detection of Ethanol \\ 3.3.1. $\mathrm{pH}$ Effect}

In the case of methyl orange, UV-Vis analysis showed that a peak shift could be induced by ethanol in $\mathrm{pH} 7, \mathrm{pH}$, and 12 solution and a peak shift in $\mathrm{pH} \mathrm{2,} \mathrm{4,} \mathrm{6,} \mathrm{and}$ 9 methyl red solutions. In the case of ethanol-methyl orange mixture, UV-Vis analysis peak shift was obtained at pH 7,9 $(\sim 489 \mathrm{~nm}$ to $\sim 509 \mathrm{~nm})$, and $12(\sim 493 \mathrm{~nm}$ to $510 \mathrm{~nm})$ with the same absorbance of 0.60 a.u., 0.581 a.u., and 0.355 a.u., respectively. The ethanol with methyl red results showed a bathochromic effect at $581 \mathrm{~nm}$ from $560 \mathrm{~nm}$ in pH 2, 4, 6 , and 9.

The iodoform test was used to detect carbonyl compounds, and as formic acid does not contain a carbonyl, it was not tested. The hydroxide ion removes acidic alpha hydrogen and forms an enolate ion in this reaction. An enolate anion displaces an iodide ion from the iodine molecule to produce $\mathrm{R}-\mathrm{CO}-\mathrm{CI}_{3}$. The hydroxide ion reforms the carbonyl group and eliminates the $\mathrm{CI}^{3-}$ anion upon bonding with the carbonyl carbon. Iodoform is precipitated in yellow color when the carboxylic acid group and the $\mathrm{CI}^{3-}$ ion react. The iodoform test was carried out to identify the detected compound using $\mathrm{pH} 9$ solution with methyl orange and methyl red. A positive iodoform test is given by the compounds having $\mathrm{CH}_{3} \mathrm{CO}$ group in their structure. Thus, ethanol gives a positive iodoform test. Due to the formation of tri-iodomethane or iodoform, the solution containing ethanol became cloudy, and then a yellow precipitate formed (Figure 8). The dye solution containing methanol had no change. 

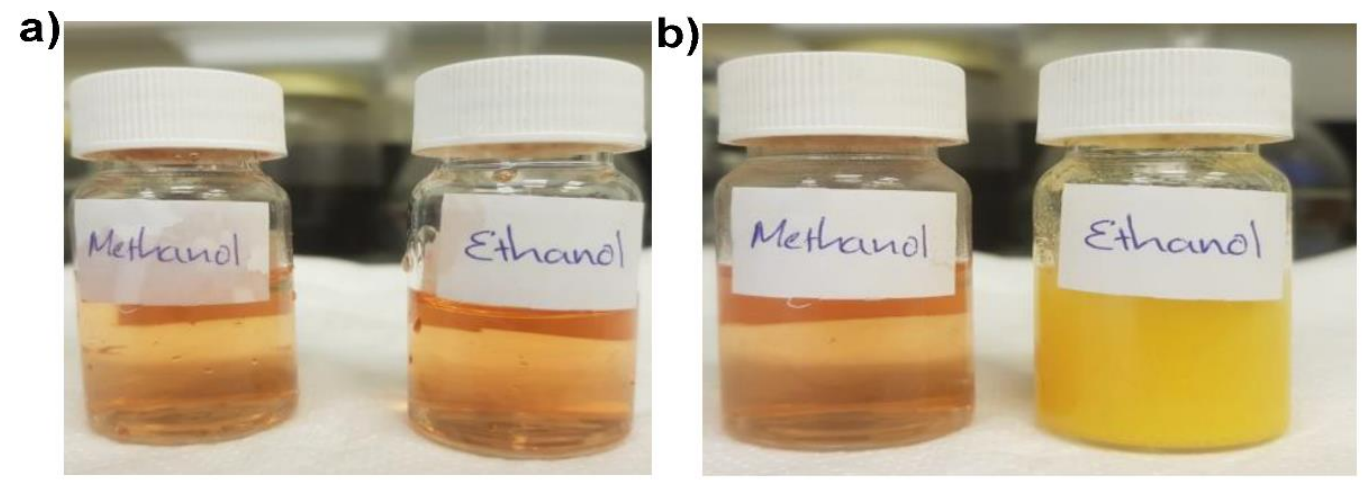

Figure 8. Test solutions of $\mathrm{pH} 9$ methyl orange solution with methanol and ethanol (a) before and (b) after the iodoform test.

\subsubsection{Concentration Effect}

Sensitivity analysis of ethanol with concentration $0.05-15 \mathrm{ppm}$ was carried out for methyl orange and methyl red dye solutions (Figure 9a). The linear fitting by considering the peak absorbance of methyl orange at $509 \mathrm{~nm}$ for different concentrations of ethanol estimated LOD as $\sim 0.0664 \mathrm{ppm}, \mathrm{R}^{2}=0.84786$. Similarly, the calibration plot of methyl red at $581 \mathrm{~nm}$ for different methanol concentrations estimated an LOD of $\sim 0.0614 \mathrm{ppm}$, $R^{2}=0.82671$. For the iodoform test, LOD was found to be $0.0609 \mathrm{ppm}$ with an $R^{2}$ value of 0.90064 . This indicates that these three systems can detect ethanol with concentrations as low as $0.0609 \mathrm{ppm}$. In the case of the iodoform test, response time was almost constant, irrespective of the change in ethanol concentration.
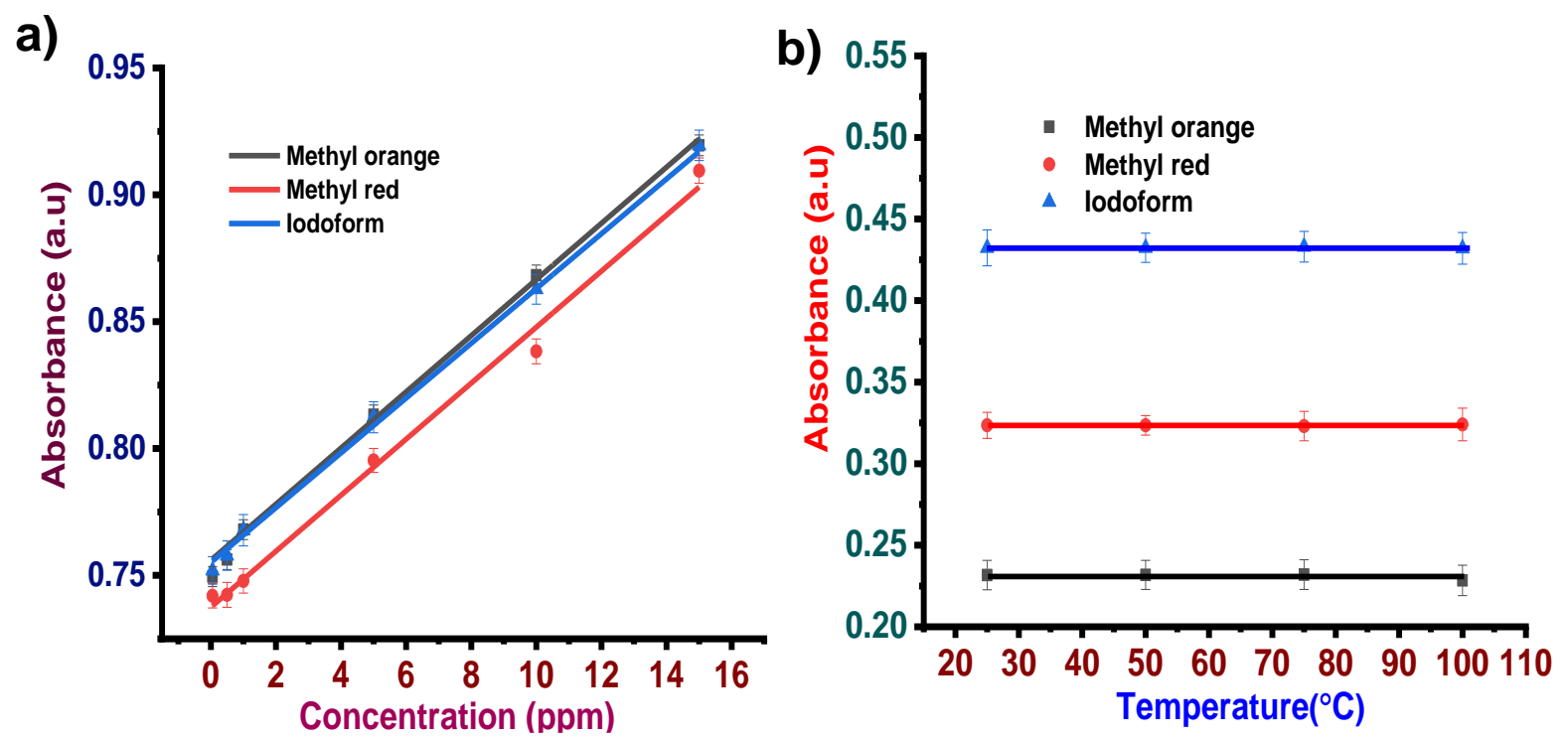

Figure 9. (a) Sensitivity analysis of formic acid in dye solutions. (b) Stability analysis of formic acid in dye solutions.

\subsubsection{Temperature Effect}

Stability analysis of ethanol was carried out in methyl orange, methyl red, and iodoform at different temperatures, $25^{\circ} \mathrm{C}, 50^{\circ} \mathrm{C}, 75^{\circ} \mathrm{C}$, and $100{ }^{\circ} \mathrm{C}$, and it showed negligible temperature effect. Figure $9 \mathrm{~b}$ shows the effect of temperature on the sensing performance of the three systems towards $0.5 \mathrm{ppm}$ ethanol. The temperature study reveals no significant effect of temperature on dye sensing. The above analysis revealed that this mode of dye sensing offers high stability towards the change in temperature, which is important for accurate test analyte sensing based on color development. 


\subsubsection{Selectivity Analysis}

Selectivity analysis was carried out for $\mathrm{pH} 9$ methyl orange dye and $\mathrm{pH} 6$ methyl red dye solutions (Figure 7). It is clear from Figure 7 that all the dyes have high selectivity in detecting ethanol.

\subsection{Evaluation of the Proposed Colorimetric Method and Validation with NMR Technique}

A portable prototype device with full functions for detecting formic acid, ethanol, and methanol was developed. Using the dyes as sensing elements, the sensor prototype showed unique RGB values upon exposure to test solutions. In the first approach, three dyes were chosen to detect each test solution at a concentration of $0.05 \mathrm{ppm}$, and the obtained RGB values were shown in Table 3.

Table 3. Analysis of F/E/M-dye mixture using sensor prototype at $0.05 \mathrm{ppm}$ concentration.

\begin{tabular}{|c|c|c|}
\hline S1. No & F/E/M-Dye Mixture & RGB Values \\
\hline 1 & A (Nil) B (Nil) C (Nil) & $265,195,10$ \\
\hline 2 & $\mathrm{~A}\left(\mathrm{FX}_{1}\right) \mathrm{B}\left(\mathrm{FX}_{1}\right) \mathrm{C}\left(\mathrm{FX}_{1}\right)$ & $245,107,80$ \\
\hline 3 & A (Nil) B (Nil) D (Nil) & $255,95,25$ \\
\hline 4 & $\mathrm{~A}\left(\mathrm{FX}_{1}\right) \mathrm{B}\left(\mathrm{FX}_{1}\right) \mathrm{D}\left(\mathrm{FX}_{1}\right)$ & $245,107,60$ \\
\hline 5 & G (Nil) H (Nil) I (Nil) & $235,103,110$ \\
\hline 6 & $\mathrm{G}\left(\mathrm{EX}_{1}\right) \mathrm{H}\left(\mathrm{EX}_{1}\right) \mathrm{I}\left(\mathrm{EX}_{1}\right)$ & $260,210,115$ \\
\hline 7 & G (Nil) H (Nil) & $235,118,85$ \\
\hline 8 & $\mathrm{G}\left(\mathrm{MX}_{1}\right) \mathrm{H}\left(\mathrm{MX}_{1}\right)$ & $275,215,96$ \\
\hline
\end{tabular}

A: Alizaringelb, B: Eosin blue, C: KMnO4, D: Phenyl red, G: Methyl orange, H: Methyl red, I: Iodine+ $\mathrm{NaOH}$ F: Formic acid, M: methanol, E: Ethanol, $X_{1}=0.05 \mathrm{ppm}, X_{2}=0.1 \mathrm{ppm}, X_{3}=0.5 \mathrm{ppm}, X_{4}=1 \mathrm{ppm}, X_{5}=5 \mathrm{ppm}$, $\mathrm{X}_{6}=10 \mathrm{ppm}, \mathrm{X}_{7}=50 \mathrm{ppm}$.

In the second approach, the test solutions in different concentrations were analyzed using the sensor prototype in different dyes. Table 4 shows the RGB values obtained for different concentrations of formic acid in different dyes.

Table 4. Analysis of formic acid in different concentrations with the dyes using sensor prototype.

\begin{tabular}{ccc}
\hline S1. No & $\begin{array}{c}\text { F/E/M-Dye Mixture } \\
\text { at Different Concentration }\end{array}$ & RGB Values \\
\hline 1 & $\mathrm{~A}(\mathrm{Nil}) \mathrm{B}(\mathrm{Nil}) \mathrm{C}(\mathrm{Nil})$ & $265,195,10$ \\
2 & $\mathrm{~A}\left(\mathrm{FX}_{2}\right) \mathrm{B}\left(\mathrm{FX}_{2}\right) \mathrm{C}\left(\mathrm{FX}_{2}\right)$ & $235,103,40$ \\
3 & $\mathrm{~A}\left(\mathrm{FX}_{3}\right) \mathrm{B}\left(\mathrm{FX}_{3}\right) \mathrm{C}\left(\mathrm{FX}_{3}\right)$ & $240,116,49$ \\
4 & $\mathrm{~A}\left(\mathrm{FX}_{4}\right) \mathrm{B}\left(\mathrm{FX}_{4}\right) \mathrm{C}\left(\mathrm{FX}_{4}\right)$ & $246,122,55$ \\
5 & $\mathrm{~A}\left(\mathrm{FX}_{5}\right) \mathrm{B}\left(\mathrm{FX}_{5}\right) \mathrm{C}\left(\mathrm{FX}_{5}\right)$ & $251,134,61$ \\
6 & $\mathrm{~A}\left(\mathrm{FX}_{6}\right) \mathrm{B}\left(\mathrm{FX}_{6}\right) \mathrm{C}\left(\mathrm{FX}_{6}\right)$ & $253,141,66$ \\
7 & $\mathrm{~A}\left(\mathrm{FX}_{7}\right) \mathrm{B}\left(\mathrm{FX}_{7}\right) \mathrm{C}\left(\mathrm{FX}_{7}\right)$ & $258,147,69$ \\
\hline
\end{tabular}

A: Alizaringelb, B: Eosin blue, C: KMnO4, D: Phenyl red, G: Methyl orange, H: Methyl red, I: Iodine+ $\mathrm{NaOH}$ F: Formic acid, M: methanol, E: Ethanol, $X_{1}=0.05 \mathrm{ppm}, \mathrm{X}_{2}=0.1 \mathrm{ppm}, \mathrm{X}_{3}=0.5 \mathrm{ppm}, \mathrm{X}_{4}=1 \mathrm{ppm}, \mathrm{X}_{5}=5 \mathrm{ppm}$, $\mathrm{X}_{6}=10 \mathrm{ppm}, \mathrm{X}_{7}=50 \mathrm{ppm}$.

In the third approach, the test solutions mixture at $0.05 \mathrm{ppm}$ was analyzed using different dyes, and the obtained RGB values are shown in Table 5. From the RGB chart obtained, we can predict the system of dye solutions that detected formic acid or methanol or ethanol, or all three together. A similar RGB chart can be created for different concentrations of test solutions. It was proved from these studies that we can similarly design the unique RGB chart for all dye solutions. These studies confirmed that this sensor prototype could detect the presence and the concentration of each test molecule and its concentration based on the RGB values. 
Table 5. Analysis of $\mathrm{F}+\mathrm{E}+\mathrm{M}$ mixture in dyes using sensor prototype for different concentrations.

\begin{tabular}{cccc}
\hline Sl. No & Solution Mixture (0.05 $\mathbf{p p m )}$ & Dyes & RGB Values \\
\hline 1 & $\mathrm{FX}_{1}+\mathrm{EX}_{1}+\mathrm{MX}$ & $\mathrm{A}-\mathrm{B}-\mathrm{C}$ & $245,107,80$ \\
2 & $\mathrm{FX}_{1}+\mathrm{EX}_{1}+\mathrm{MX} \mathrm{X}_{1}$ & $\mathrm{~A}-\mathrm{B}-\mathrm{D}$ & $245,107,60$ \\
3 & $\mathrm{FX}_{1}+\mathrm{EX}_{1}+\mathrm{MX} \mathrm{X}_{1}$ & $\mathrm{~A}-\mathrm{B}-\mathrm{G}$ & $245,107,275$ \\
4 & $\mathrm{FX}_{1}+\mathrm{EX}_{1}+\mathrm{MX} \mathrm{X}_{1}$ & $\mathrm{~A}-\mathrm{B}-\mathrm{H}$ & $245,107,215$ \\
5 & $\mathrm{FX}_{1}+\mathrm{EX}_{1}+\mathrm{MX} X_{1}$ & $\mathrm{~A}-\mathrm{B}-\mathrm{I}$ & $245,107,115$ \\
\hline
\end{tabular}

Currently, related conventional detection technologies mainly include chromatography (high-performance liquid chromatography and ion chromatography), spectroscopy (spectrophotometry), biological detection, etc. [9-11]. However, the technologies mentioned above generally involve expensive equipment and a complicated analysis process and are unsuitable for in-field or real-time testing [28]. In an economic aspect, the choice of the proposed colorimetric method is much higher than the classical detection methods. This IoT-based prototype is cost-effective instead of these high-cost and heavy-duty instruments. The proposed method will only cost around USD 20, whereas the classic instrument costs 10 times higher.

Furthermore, this colorimetric approach would provide results in seconds without taking hours, as would classical methods. Different analysis perspectives were carried out to determine the efficiency of the colorimetric method with the NMR technique. NMR integration results generally agree with those obtained by colorimetry, with some overestimation for related compounds probably due to peak overlap and subsequent integral errors and an apparent relative lower estimation for the target compound. Figure 10 compares the efficiency of NMR and colorimetric data for methanol.

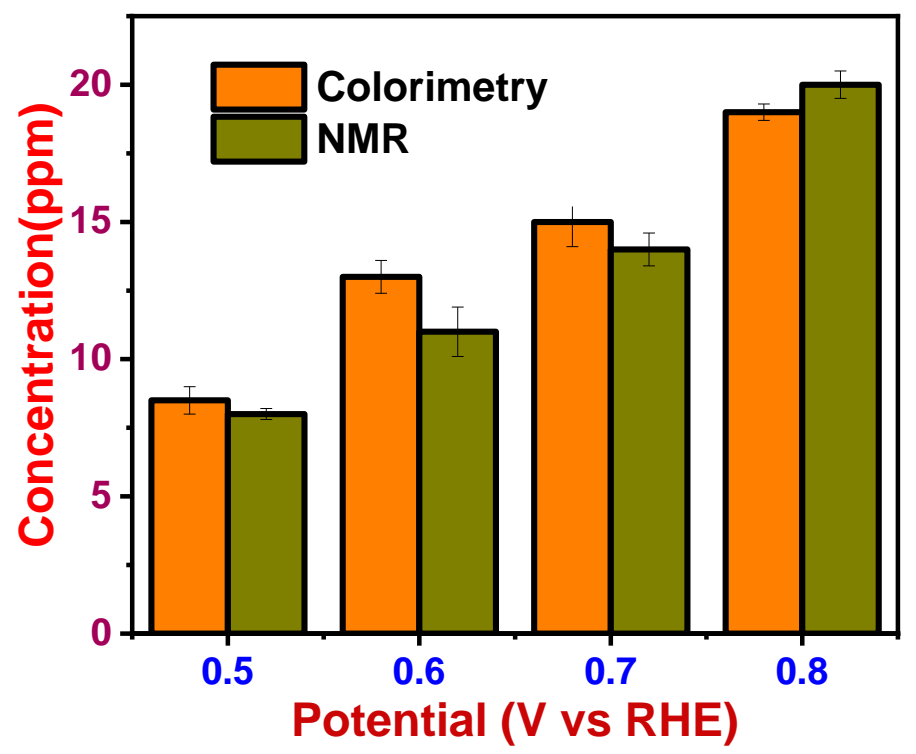

Figure 10. Comparison of NMR data and colorimetric data for methanol.

The quantification data of methanol at the potential range of $0.5-0.8 \mathrm{~V}$ shows the concentration in the range of 8-19 ppm in NMR and 8.5-20 ppm in this developed sensor prototype. It is clear from these values that this new approach of colorimetric detection and quantification of formic acid, methanol, and ethanol would be a new accurate method for chemical analysis. It can replace various heavy-duty instruments used for the same purpose. The designed sensor prototype is portable and easily accessed with any Bluetooth device. The results obtained demonstrate the potential of the colorimetric method for detecting value-added products generated by recycling $\mathrm{CO}_{2}$.

Apart from detecting the three compounds, this IoT-based colorimetric sensor has also found other practical applications. As formic acid is the main toxic compound produced 
during methyl alcohol metabolism, it accumulates in the body. It is the main reason for toxic effects and death through methanol poisoning [29-31]. Commonly reported adverse effects of high serum concentrations of formic acid include visual damage, optical nerve injury, abdominal problems, nausea, and headache. Subsequently, high formic acid concentrations result in respiratory problems and renal failure, leading to coma and death [32]. Therefore, it seems necessary to determine the serum concentrations of methanol and formic acid to evaluate the causes of these observed adverse effects.

Similarly, ethanol is one of the breath biomarkers and is key to diagnosing and managing diabetic ketoacidosis (DKA) in patients with type 1 diabetes. It may also be of increasing importance to detect euglycemic ketoacidosis in patients with type 1 or type 2 diabetes or heart failure, treated with sodium-glucose transporter-2 inhibitors (SGLT2-i). Analysis of breath ethanol is also important for forensic purposes in diagnosing metabolic diseases and monitoring medical treatment [33].

\section{Conclusions}

In summary, we proposed a novel IoT-based colorimetric strategy for detecting methanol, ethanol, and formic acid obtained after the conversion of $\mathrm{CO}_{2}$. In this approach, the dye solutions act as sensing elements, and these multisensors help us provide more accurate results. From the RGB chart obtained, we predicted the system of dye solutions that detected formic acid or methanol or ethanol, or all three together, and the concentration of the three compounds. The developed method exhibited excellent response with a short response time of around $2 \mathrm{~s}$ and high selectivity with a low detection limit of 0.03-0.06 ppm towards detected compounds. This advanced colorimetric method is cost-effective and straightforward. These studies prove that it is possible to design a unique RGB chart for all dye solutions to their specific test analyte. While investigating the comparative efficiency of both NMR and colorimetry for the three compounds in terms of cost and accuracy helps to conclude that this dye system-based approach is more efficient than heavy-duty instruments, it can be extended to detecting these molecules and other analytical strategies, which holds great potential for detecting different molecules in different application scenarios.

Author Contributions: Conceptualization, K.K.S.; methodology, M.S.S.; software, M.R.M.; validation, M.R.M., M.G. and K.K.S.; formal analysis, M.S.S.; investigation, M.S.S.; resources, M.S.S. and M.G.; data curation, M.S.S.; writing—original draft preparation, M.S.S.; writing—review and editing, M.R.M., M.G., B.K., A.M.A. and K.K.S.; visualization, M.R.M.; supervision, K.K.S.; project administration, K.K.S.; funding acquisition, K.K.S. All authors have read and agreed to the published version of the manuscript.

Funding: This research was funded by Qatar National Research Fund (a member of the Qatar Foundation) grant number NPRP11S-1221-170116 and the APC was funded by Qatar National Research Fund.

Institutional Review Board Statement: Not applicable.

Informed Consent Statement: Not applicable.

Data Availability Statement: Not applicable.

Acknowledgments: This work was carried out by the NPRP11S-1221-170116 from the Qatar National Research Fund (a member of the Qatar Foundation). The statements made herein are exclusively the accountability of the authors.

Conflicts of Interest: The authors declare that they have no conflict of interest.

\section{References}

1. Khalil, M.; Gunlazuardi, J.; Ivandini, T.A.; Umar, A. Photocatalytic Conversion of $\mathrm{CO}_{2}$ Using Earth-Abundant Catalysts: A Review on Mechanism and Catalytic Performance. Renew. Sustain. Energy Rev. 2019, 113, 109246. [CrossRef]

2. Wei, Y.; Li, Y.; Wu, M.; Li, Y. The Decomposition of Total-Factor $\mathrm{CO}_{2}$ Emission Efficiency of 97 Contracting Countries in Paris Agreement. Energy Econ. 2019, 78, 365-378. [CrossRef]

3. Detz, R.J.; van der Zwaan, B. Transitioning towards Negative $\mathrm{CO}_{2}$ Emissions. Energy Policy 2019, 133, 110938. [CrossRef] 
4. Kaya, Y.; Yamaguchi, M.; Geden, O. Towards Net Zero $\mathrm{CO}_{2}$ Emissions without Relying on Massive Carbon Dioxide Removal. Sustain. Sci. 2019, 14, 1739-1743. [CrossRef]

5. Rispoli, A.L.; Verdone, N.; Vilardi, G. Green Fuel Production by Coupling Plastic Waste Oxy-Combustion and PtG Technologies: Economic, Energy, Exergy and $\mathrm{CO}_{2}$-Cycle Analysis. Fuel Process. Technol. 2021, 221, 106922. [CrossRef]

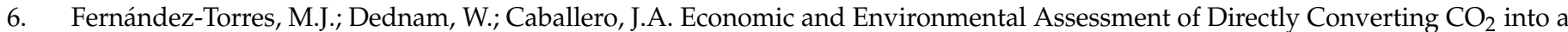
Gasoline Fuel. Energy Convers. Manag. 2022, 252, 115115. [CrossRef]

7. Yang, Q.; Zhang, J.; Chu, G.; Zhou, H.; Zhang, D. Optimal Design, Thermodynamic and Economic Analysis of Coal to Ethylene Glycol Processes Integrated with Various Methane Reforming Technologies for $\mathrm{CO}_{2}$ Reduction. Energy Convers. Manag. 2021, 244, 114538. [CrossRef]

8. Rosli, S.-S.; Lim, J.-W.; Jumbri, K.; Lam, M.-K.; Uemura, Y.; Ho, C.-D.; Tan, W.-N.; Cheng, C.-K.; Kadir, W.-N.-A. Modeling to Enhance Attached Microalgal Biomass Growth onto Fluidized Beds Packed in Nutrients-Rich Wastewater Whilst Simultaneously Biofixing $\mathrm{CO}_{2}$ into Lipid for Biodiesel Production. Energy Convers. Manag. 2019, 185, 1-10. [CrossRef]

9. Reddy, M.S.B.; Ponnamma, D.; Sadasivuni, K.K.; Kumar, B.; Abdullah, A.M. Carbon Dioxide Adsorption Based on Porous Materials. RSC Adv. 2021, 11, 12658-12681. [CrossRef]

10. Kannan, K.; Sadasivuni, K.K.; Abdullah, A.M.; Kumar, B. Current Trends in MXene-Based Nanomaterials for Energy Storage and Conversion System: A Mini Review. Catalysts 2020, 10, 495. [CrossRef]

11. Hepburn, C.; Adlen, E.; Beddington, J.; Carter, E.A.; Fuss, S.; Mac Dowell, N.; Minx, J.C.; Smith, P.; Williams, C.K. The Technological and Economic Prospects for $\mathrm{CO}_{2}$ Utilization and Removal. Nature 2019, 575, 87-97. [CrossRef] [PubMed]

12. Bonura, G.; Todaro, S.; Frusteri, L.; Majchrzak-Kucęba, I.; Wawrzyńczak, D.; Pászti, Z.; Tálas, E.; Tompos, A.; Ferenc, L.; Solt, H.; et al. Inside the Reaction Mechanism of Direct $\mathrm{CO}_{2}$ Conversion to DME over Zeolite-Based Hybrid Catalysts. Appl. Catal. $B$ Environ. 2021, 294, 120255. [CrossRef]

13. Al-Juboori, O.; Sher, F.; Khalid, U.; Niazi, M.B.K.; Chen, G.Z. Electrochemical Production of Sustainable Hydrocarbon Fuels from $\mathrm{CO}_{2}$ Co-Electrolysis in Eutectic Molten Melts. ACS Sustain. Chem. Eng. 2020, 8, 12877-12890. [CrossRef]

14. Zheng, Y.; Vasileff, A.; Zhou, X.; Jiao, Y.; Jaroniec, M.; Qiao, S.-Z. Understanding the Roadmap for Electrochemical Reduction of $\mathrm{CO}_{2}$ to Multi-Carbon Oxygenates and Hydrocarbons on Copper-Based Catalysts. J. Am. Chem. Soc. 2019, 141, 7646-7659. [CrossRef] [PubMed]

15. Nitopi, S.; Bertheussen, E.; Scott, S.B.; Liu, X.; Engstfeld, A.K.; Horch, S.; Seger, B.; Stephens, I.E.L.; Chan, K.; Hahn, C.; et al Progress and Perspectives of Electrochemical $\mathrm{CO}_{2}$ Reduction on Copper in Aqueous Electrolyte. Chem. Rev. 2019, 119, $7610-7672$. [CrossRef]

16. Zhang, F.; Co, A.C. Rapid Product Analysis for the Electroreduction of $\mathrm{CO}_{2}$ on Heterogeneous and Homogeneous Catalysts Using a Rotating Ring Detector. J. Electrochem. Soc. 2020, 167, 046517. [CrossRef]

17. Kai, T.; Zhou, M.; Duan, Z.; Henkelman, G.A.; Bard, A.J. Detection of $\mathrm{CO}_{2}{ }^{\bullet-}$ in the Electrochemical Reduction of Carbon Dioxide in N,N-Dimethylformamide by Scanning Electrochemical Microscopy. J. Am. Chem. Soc. 2017, 139, 18552-18557. [CrossRef]

18. Hao, M.; Zhang, R.; Jia, X.; Gao, X.; Gao, W.; Cheng, L.; Qin, Y. A Polymer Based Self-Powered Ethanol Gas Sensor to Eliminate the Interference of Ultraviolet Light. Sens. Actuators A Phys. 2021, 332, 113173. [CrossRef]

19. Maldonado-Arriola, J.A.; Sánchez-Zeferino, R.; Álvarez-Ramos, M.E. Photoluminescent Properties of ZnO Nanorods Films Used to Detect Methanol Contamination in Tequila. Sens. Actuators A Phys. 2020, 312, 112142. [CrossRef]

20. Ghorbani, H.; Nezami, A.; Sheikholeslami, B.; Hedjazi, A.; Ahmadimanesh, M. Simultaneous Measurement of Formic Acid, Methanol and Ethanol in Vitreous and Blood Samples of Postmortem by Headspace GC-FID. J. Occup. Med. Toxicol. 2018, 13, 1. [CrossRef]

21. Liu, B.; Zhuang, J.; Wei, G. Recent Advances in the Design of Colorimetric Sensors for Environmental Monitoring. Environ. Sci. Nano 2020, 7, 2195-2213. [CrossRef]

22. Ko, E.; Hur, W.; Son, S.E.; Seong, G.H.; Han, D.K. Au Nanoparticle-Hydrogel Nanozyme-Based Colorimetric Detection for on-Site Monitoring of Mercury in River Water. Microchim. Acta 2021, 188, 382. [CrossRef]

23. Ying, N.; Wang, Y.; Song, X.; Yang, L.; Qin, B.; Wu, Y.; Fang, W. Lateral Flow Colorimetric Biosensor for Detection of Vibrio Parahaemolyticus Based on Hybridization Chain Reaction and Aptamer. Microchim. Acta 2021, 188, 381. [CrossRef]

24. Singh, H.; Bamrah, A.; Bhardwaj, S.K.; Deep, A.; Khatri, M.; Brown, R.J.C.; Bhardwaj, N.; Kim, K.-H. Recent Advances in the Application of Noble Metal Nanoparticles in Colorimetric Sensors for Lead Ions. Environ. Sci. Nano 2021, 8, 863-889. [CrossRef]

25. Maurya, M.R.; Onthath, H.; Morsy, H.; Riyaz, N.-U.-S.; Ibrahim, M.; Ahmed, A.E.; Abuznad, R.; Alruwaili, A.; Alsaedi, F.; Kasak, P.; et al. Colorimetry-Based Detection of Nitric Oxide from Exhaled Breath for Quantification of Oxidative Stress in Human Body. Healthcare 2021, 9, 1055. [CrossRef] [PubMed]

26. Matsukawa, Y.; Umemura, K. Detection of Redox Properties of (6,5)-Enriched Single-Walled Carbon Nanotubes Using Potassium Permanganate $\left(\mathrm{KMnO}_{4}\right)$. C 2020, 6, 30. [CrossRef]

27. Bononi, F.C.; Chen, Z.; Rocca, D.; Andreussi, O.; Hullar, T.; Anastasio, C.; Donadio, D. Bathochromic Shift in the UV-Visible Absorption Spectra of Phenols at Ice Surfaces: Insights from First-Principles Calculations. J. Phys. Chem. A 2020, 124, 9288-9298. [CrossRef]

28. Sun, L.; Rotaru, A.; Robeyns, K.; Garcia, Y. A Colorimetric Sensor for the Highly Selective, Ultra-Sensitive, and Rapid Detection of Volatile Organic Compounds and Hazardous Gases. Ind. Eng. Chem. Res. 2021, 60, 8788-8798. [CrossRef] 
29. Jacobsen, D.; Webb, R.; Collins, T.D.; McMartin, K.E. Methanol and Formate Kinetics in Late Diagnosed Methanol Intoxication. Med. Toxicol. Advers. Drug Exp. 1988, 3, 418-423. [CrossRef]

30. Kerns, W.; Tomaszewski, C.; McMartin, K.; Ford, M.; Brent, J.; META Study Group. Methylpyrazole for Toxic Alcohols Formate Kinetics in Methanol Poisoning. J. Toxicol. Clin. Toxicol. 2002, 40, 137-143. [CrossRef]

31. Treichel, J.L.; Henry, M.M.; Skumatz, C.M.B.; Eells, J.T.; Burke, J.M. Formate, the Toxic Metabolite of Methanol, in Cultured Ocular Cells. Neurotoxicology 2003, 24, 825-834. [CrossRef]

32. Bursová, M.; Hložek, T.; Čabala, R. Simultaneous Determination of Methanol, Ethanol and Formic Acid in Serum and Urine by Headspace GC-FID. J. Anal. Toxicol. 2015, 39, 741-745. [CrossRef] [PubMed]

33. Pham, Y.L.; Beauchamp, J. Breath Biomarkers in Diagnostic Applications. Molecules 2021, 26, 5514. [CrossRef] [PubMed] 